\title{
Mundos pequenos, produção acadêmica e grafos de colaboração: um estudo de caso dos Enanpads*
}

\author{
Mauro Joaquim da Costa Braga** \\ Luiz Flavio Autran Monteiro Gomes*** \\ Marco Aurélio Ruediger****
}

\begin{abstract}
SumÁrio: 1. Introdução; 2. Revisão da literatura; 3. Metodologia utilizada; 4. Resultados e discussão.

Summary: 1. Introduction; 2. Literature review; 3. Adopted methodology; 4. Results and discussion.
\end{abstract}

Palavras-chave: redes sociais; teoria dos grafos; comunidades científicas; endogenia.

KEY WORDs: social networks; graph theory; scientific community; endogeny.

Utilizando a base de dados dos trabalhos publicados nos Enanpads realizados em 2002-04, este artigo focaliza a área de administração da informação para realizar um estudo exploratório sobre a formação de padrões nas estruturas de disseminação do conhecimento acadêmico no Brasil, apoiado nos conceitos oriundos da análise das redes sociais e conjugados com a base proveniente da teoria dos grafos e em recursos computacionais. Procurou-se mapear os fluxos de informações que possibilitam as trocas de conhecimento através das ligações existentes no meio acadêmico. Os resultados indicam a necessidade de ampliar e estreitar os laços entre os autores, notadamente os que possuem algum grau de centralidade local, no intuito de obter o fortalecimento das instituições de ensino, de forma a quebrar as resistências à produção conjunta entre elas, em detrimento do padrão de reprodução endógena detectado.

\footnotetext{
* Artigo recebido em fev. 2006 e aceito em mar. 2007.

** MSc. Gerente do Departamento de Energia Elétrica do Banco Nacional de Desenvolvimento Econômico e Social (BNDES). Endereço: Rua Dr. Júlio Otoni, 282 - Santa Teresa — CEP 20241400, Rio de Janeiro, Brasil. E-mail: mbraga@bndes.gov.br.

** PhD. Professor titular das Faculdades Ibmec-Rio. Endereço: Av. Rio Branco, 108, 5o andar — Centro - CEP 20040-001, Rio de Janeiro, Brasil. E-mail: autran@ibmecrj.br.

**** Professor associado da Escola Brasileira de Administração Pública e de Empresas da Fundação Getulio Vargas (Ebape/FGV). Endereço: Praia de Botafogo, 190, 5o andar — Botafogo — CEP 22253-900, Rio de Janeiro, Brasil. E-mail: ruediger@fgv.br.
} 
Small worlds, academic production and collaborative graphs: a case study of the Enanpads

This article uses the database of papers published in the Enanpad proceedings in the 2002-04 period, focusing in the information management area in order to carry out an exploratory study of the patterns of dissemination of academic knowledge in Brazil. The framework of the study relies is that of graph-theoretical, computationalbased social network analysis. The authors then map the information flows that allow knowledge exchanges circulating through the existing connections in the academic environment. Results from the analysis suggest the need for broadening and strengthening linkages among contributing authors. This seems to be most important for authors with some degree of local centrality, because this would probably lead to overcoming any barriers to joint scientific production, as opposed to the prevailing pattern of endogenous production.

\section{Introdução}

Uma rede social é um grupo de pessoas, de organizações ou de outros relacionamentos, conectados por um conjunto de relações sociais, como as amizades, o trabalho em conjunto ou a simples troca de informações. A análise das redes sociais procura formatar os percursos existentes nas relações entre as pessoas, as organizações, ou os Estados, por exemplo (Garton, 1997). Na terminologia das redes sociais, as pessoas ou grupos são denominados como atores e as conexões como ligações. As unidades de análise das redes são os conjuntos compostos por grupos de indivíduos e suas inter-relações (Hanneman, 2001).

Os estudos sobre o tema remontam a mais de meio século, e os atores inicialmente enfocados incluíram grupos de mulheres (Davis, Gardner e Gardner, 1941), sistemas sociais (Simmel, 1950; Baltzel, 1958), estudantes (Rapoport e Horvath, 1951; Fararo e Sunshine, 1964) e posições no mercado de trabalho (Granovetter, 1973). Mais recentemente, redes que pudessem ser mais bem documentadas e das quais fossem obtidas estatísticas confiáveis tornaram-se objeto de estudo, tais como redes de internet (Faloutsos, Faloutsos e Faloutsos, 1999), relações de negócios do tipo "pessoa a pessoa" (p2p) (Adamic et al., 2001) e redes de e-mail (Newman, Forrest e Balthrop, 2002).

A rede de colaboração formada para a produção de textos científicos de uma maneira geral é bastante ampla e transcende os limites institucionais. Um exemplo digno de nota é o do matemático húngaro Paul Erdös (1913-96), que escreveu e publicou mais de 1.500 artigos em conjunto com diferentes co-autores (Batagelj e Mrvar, 2004), tendo sido premiado pela American Mathematical Society, em 1951, e recebido o Wolf Prize, em 1983. Segundo Barabási (2003), o entendimento das redes é vital não só nos negócios e na ciência, mas também 
em atividades rotineiras. Identificar como a disseminação do conhecimento permeia nosso meio acadêmico é uma forma de contribuir para que as relações já existentes sejam expandidas, que novas relações sejam criadas e que se pense na formação de uma rede estruturada, no sentido do desenvolvimento do conhecimento comum.

Partindo de colocação citada na apresentação do XXVII Encontro Nacional de Pós-graduação e Pesquisa em Administração (Enanpad, 2003): “(...) uma comunidade acadêmica não se torna substantiva apenas com base na produção científica individual, por mais relevante que ela possa ser. A interação entre pares, entre grupos e organizações, é elemento essencial para a construção de uma comunidade sólida", e este estudo pretende investigar como são formadas as estruturas das redes sociais de colaboração entre diversos autores, as quais amparam a divulgação, a validação e o surgimento de novas áreas de pesquisa nos meios acadêmicos, por meio de um estudo de caso dos Enanpads. Para tanto, pretende-se responder às seguintes questões:

$\checkmark$ Como é construída ou estruturada essa comunidade acadêmica?

- Como se processam as interações entre seus participantes?

- Que tipo de resultado é gerado pela comunidade acadêmica quanto aos novos relacionamentos, apregoados pelos Enanpads?

、 Quais são as medidas quantitativas associadas às redes de difusão de conhecimento existentes em nossas universidades?

A análise aqui apresentada restringiu-se à área de administração da informação (ADI) dos Enanpads, por três motivos:

v pura e simplesmente, por ser a primeira a ser apresentada na listagem dos trabalhos publicados;

v por razões mais à frente abordadas, o incremento no número de atores nas redes analisadas faz com que o número de ligações correspondentes cresça, no mínimo, de forma logarítmica, levando a que o tempo utilizado no processamento dos dados se torne indesejável para os objetivos propostos neste artigo;

v o incremento do número de atores prejudica os resultados visuais básicos que pretendemos obter. Entende-se que as restrições apresentadas não invalidarão os resultados obtidos, uma vez que a área de ADI é uma amostra razoável do que acontece em todas as outras áreas do Enanpad, conforme apresentado na tabela 1 : 
Tabela 1

\section{Participação da ADI nos Enanpads}

\begin{tabular}{|cccccc|}
\hline \multirow{2}{*}{ Ano } & \multirow{2}{*}{$\begin{array}{c}\text { Número de trabalhos } \\
\text { apresentados (total) }\end{array}$} & \multirow{2}{*}{$\begin{array}{c}\text { Número de trabalhos } \\
\text { apresentados (ADI) }\end{array}$} & \multicolumn{3}{c|}{ Participação (\%) } \\
\cline { 5 - 6 } 2004 & 790 & 38 & 4,8 & 3,3 & 8,5 \\
2003 & 630 & 32 & 5,1 & 3,5 & 8,7 \\
2002 & $>500$ & 54 & 10,8 & 1,6 & 11,2 \\
\hline
\end{tabular}

* Participação percentual de outras áreas dos Enanpads.

\section{Revisão da literatura}

A ciência da análise das redes sociais desenvolveu-se em estágios distintos, sendo seus conceitos originais fortemente baseados nas ciências sociais, às quais posteriormente foram conectados os trabalhos oriundos da teoria dos grafos. Mais recentemente, o explosivo crescimento das técnicas e dos recursos computacionais permitiu que essas duas abordagens, em conjunto, produzissem resultados satisfatórios, mesmo para os que não possuem formação matemática sólida, por meio de softwares utilizáveis em pesquisas de análise de redes sociais (INSNA, 2004).

Certamente qualquer um de nós já passou pela experiência de, conversando com pessoas até então totalmente estranhas, descobrir que esse novo contato possui algum outro contato em comum com pessoas mais próximas de nossas relações cotidianas. Nessas situações, nosso pensamento é: "Que mundo pequeno, não?”. Analisando as probabilidades estatísticas, veremos que elas são infinitesimais. Mas o termo coincidência não é normalmente aceito pelos cientistas, que sempre procuraram determinar como se comportam os fenômenos da natureza.

A característica básica dos dados das ciências sociais é que elas são direcionadas por valores culturais e por símbolos; assim, constituem-se por maneiras, motivos, definições e caracterizações, significando que a produção dos dados envolve um processo de interpretação. Os principais tipos de dados são os "dados atribuídos" e os "dados relacionados".

Dados atribuídos dizem respeito às atitudes, às opiniões e aos padrões dos agentes, de forma que eles se relacionam às propriedades, às qualidades ou às características a que pertencem os indivíduos ou os grupos.

Dados relacionados são contatos, relações ou conexões dos agregados dos grupos e de seus cruzamentos, que são relacionados de um agente para o outro 
e, portanto, não podem ser reduzidos às propriedades dos agentes individuais. Os métodos apropriados aos dados relacionados são os da análise de redes, onde as relações são tratadas expressando as ligações que ocorrem entre os agentes. As análises de redes consistem em uma massa qualitativa de medidas das estruturas de rede (Scott, 2004).

\section{A análise das redes sociais}

A análise das redes sociais desenvolveu-se a partir dos conceitos estruturais do antropólogo Radcliffe-Brown. Em 1930-70, um número crescente de antropólogos sociais e de sociólogos começou a trabalhar sobre os conceitos de "estrutura social" de Radcliffe-Brown e tentar decifrar as metáforas da vida social por ele utilizadas. Dessas metáforas, sobressaiu-se a da "rede social"; os pesquisadores começaram a investigar a "densidade" e a "textura" das redes sociais estudadas. A partir da década de 1950, um grupo pequeno de especialistas deu início à conceituação, com maior propriedade, da tradução dessas metáforas, e, a partir de 1970, diversas técnicas de trabalho e de aplicações especiais apareceram. Dessas pesquisas emergiram os conceitos-chave da análise das redes sociais.

Segundo Scott (2004), três linhas no desenvolvimento da atual análise das redes sociais se destacam: a dos analistas sociométricos, que produziram técnicas avançadas pelo uso de métodos da teoria dos grafos; a dos pesquisadores de Harvard dos anos 1930, que exploraram as propriedades das relações interpessoais e a formação de cliques; e a dos antropólogos de Manchester, que construíram suas teorias sobre as duas vertentes anteriores.

Na linha dos analistas sociométricos, os trabalhos de Köhler (1925 apud Scott, 2004) deram início à tradição da gestalt na psicologia, que envolveu uma ruptura com os padrões de organização por meio dos quais os pensamentos e as percepções são estruturados; essa vertente enfatizou a influência da organização do grupo e de seu ambiente social associado às percepções individuais. Desses teóricos, destacam-se Kurt Lewin e Jacob Moreno.

Moreno (1934 apud Scott, 2004) explorou as possibilidades do uso de métodos psicoterapêuticos para descobrir a estrutura das escolhas de amizades. "Sociometria", embora seja particularmente associada a Moreno, é uma forma de descrição do estilo geral de pesquisa que surgiu com a tradição da gestalt; seu trabalho foi fortemente direcionado por uma orientação terapêutica das relações interpessoais e seus conceitos eram baseados em idéias clássicas de sociólogos alemães, tais como Weber, Töennies e Simmel. Sua meta era investigar como o bem-estar psicológico é relacionado com as questões estruturais do que ele de- 
nominou "configurações sociais". Essas configurações eram formadas a partir de padrões concretos de escolhas interpessoais nas quais as pessoas estão envolvidas e representam a base sobre a qual há a "agregação social" de larga escala.

Atribui-se a Moreno o desenvolvimento do "sociograma" como uma forma de representação das propriedades formais das configurações sociais; essas poderiam ser representadas em diagramas nos quais os indivíduos eram representados por "pontos" e suas relações sociais por "linhas" (figura 1). Para ele, as configurações sociais possuíam estruturas definidas e discerníveis, e o mapeamento dessas estruturas possibilitava ao pesquisador visualizar os canais de fluxo de informações.

\section{O sociograma de Moreno}

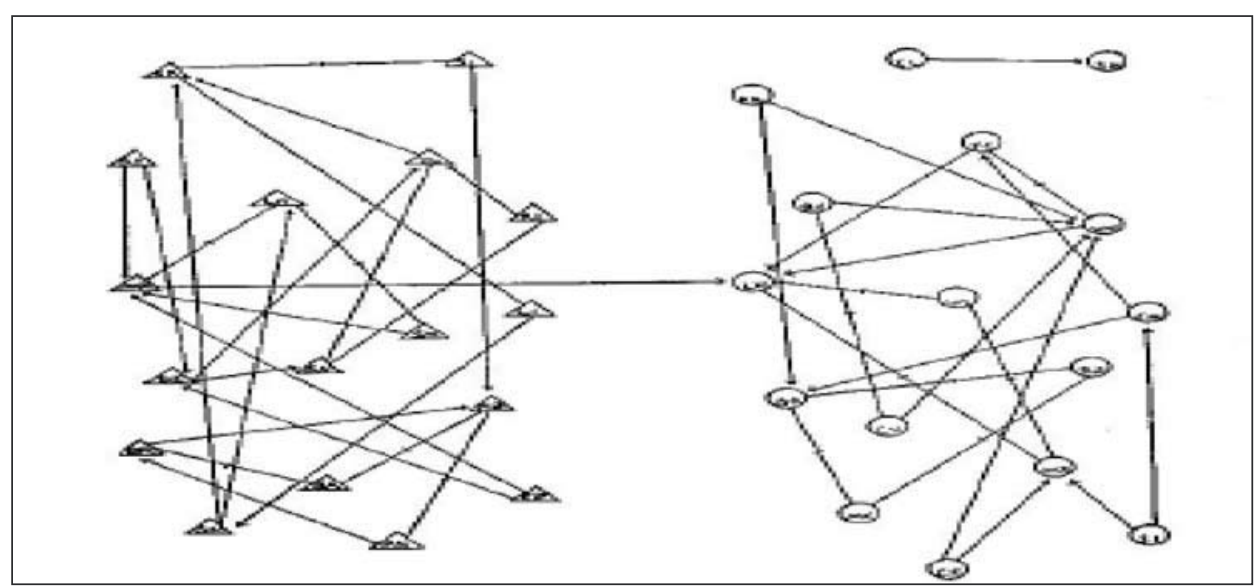

Fonte: Freeman (2002:2).

Nota: $\Delta=$ grupamento dos homens, $\mathrm{O}=$ grupamento das mulheres, $-=$ ligações entre esses dois grupamentos nas relações de amizade entre alunos de uma escola.

Lewin (1936 apud Scott, 2004), por sua vez, propôs que o comportamento dos grupos devia ser observado pelo campo das forças sociais no qual o grupo se localizava. Um grupo social existia em um "campo", um "espaço" social que compreendia o grupo, em conjunto com o ambiente do grupo que o envolvia, o qual, por sua vez, não era visto como algo puramente externo e independente do grupo. As propriedades estruturais desse espaço social poderiam ser analisadas por meio de técnicas matemáticas da teoria da topologia. A meta da "teoria do campo" é explorar, em termos matemáticos, a interdependência entre o grupo e o ambiente em um sistema de relações. Em uma abordagem topológica, o campo social é visto como composto por "pontos" 
conectados por "caminhos". Os pontos representam as pessoas, suas metas ou suas ações, e os caminhos representam as seqüências das interações ou as causas que os conectam. Os caminhos que se desenvolvem entre os pontos os conectam e as propriedades dos caminhos dividem um campo em um número discreto de regiões. Cada região é separada das outras pela ausência de ligações entre elas. As oportunidades que os indivíduos têm para se mover em seu mundo seriam determinadas, então, pelas limitações entre as diferentes regiões do campo no qual elas se localizam. As restrições impostas por esses limites são as "forças" que determinam o conhecimento do grupo. O campo social total, no entanto, é um campo de forças agindo sobre os membros do grupo e moldando suas ações e experiências.

Cartwright foi de importância particular na construção dos insights de Lewin. Junto com o matemático Harary, iniciou a aplicação da teoria dos grafos ao comportamento dos grupos (Cartwright e Harary, 1956, 1977; Bavelas, 1950 apud Scott, 2004). Newcomb (1953, apud ibidem) propôs que havia uma tendência a que duas pessoas próximas a uma outra adotassem atitudes similares frente a terceiros. Os pesquisadores puderam, assim, construir modelos da interdependência sistemática entre as atitudes tomadas por indivíduos diferentes dentro de um grupo.

Muitas das idéias que emergiram da tradição sociométrica de pesquisas de grupos pequenos foram tomadas por pesquisadores com um interesse maior em teorias gerais de sistemas e nos aspectos matemáticos das ações racionais. Estudos iniciais efetuados por Solomonoff e Rapoport (1951 apud Scott, 2004) exploraram a disseminação de doenças de uma pessoa para outra por meio de cadeias de contato, deduzindo modelos de previsão epidemiológica de contágio, o que auxiliou e estimulou o interesse na aplicação de idéias similares para a transmissão de idéias e inovações (Fararo e Sunshine, 1964; Coleman, Katz e Menzel, 1966; apud ibidem).

Scott (2004) indica que, pela escola de Harvard, trabalhos teóricos na tradição sociométrica envolveram consideráveis esforços para revelar os meios de decomposição das redes em seus subgrupos constituintes. Essa procura pelo que muitos denominaram "cliques", "clusters" ou "blocos" foi alvo de pesquisas que se desenvolveram na Universidade de Harvard durante as décadas de 1930 e 1940. A investigação de "relações informais" em sistemas de larga escala conduziu a descobertas empíricas de que esses sistemas continham subgrupos coesivos; a questão era descobrir técnicas que pudessem revelar as estruturas dos subgrupos de qualquer sistema social para os quais fossem disponíveis dados relacionais. Radcliffe-Brown e Durkheim foram os mais influentes nessa tradição de pesquisas, tendo influenciado os trabalhos de W. Lloyd Warner e de Elton Mayo. 
Os conceitos psicológicos de Mayo para a motivação individual foram complementados pelo crescente interesse nos componentes "não-racionais" das ações. Para Mayo (apud Scott, 2004), as ações econômicas não eram de natureza puramente racional, mas sim estruturadas por sentimentos não-racionais, tais como os de solidariedade dos grupos. Ele notou que uma elite gerencial reconhecia a influência das relações dos grupos na motivação econômica e assim poderia obter maior sucesso no controle do comportamento dos trabalhadores.

Hawtorne (apud Scott, 2004) estudou o ambiente natural de uma fábrica - a Western Electric Company, próxima a Chicago, entre 1924-33, e que representou um dos eventos históricos mais importantes no desenvolvimento da psicologia industrial/organizacional. Essas pesquisas são referidas coletivamente como os estudos de Hawthorne - e observou que havia uma "organização informal" na formação das equipes, em oposição à organização formal que era estabelecida pelo diagrama de gerenciamento da organização. Os subgrupos eram aqueles que os próprios trabalhadores reconheciam como elementos importantes de sua situação.

Warner e Lunt (1941 apud ibidem) realizaram estudos que enfatizavam fatores como estabilidade, coesão e integração na estruturação de comunidades; eles enfatizaram que a organização social de uma comunidade consistia em uma rede de relações pelas quais as pessoas interagiam umas com as outras; a configuração social que compreendia uma comunidade consistia em vários subgrupos, tais como as famílias, as igrejas, as classes sociais e as associações. Por meio desses estudos, descobriram o que conceituaram como um "clique": uma associação informal de pessoas por meio das quais há um grau de sentimento de grupo e de intimidade e na qual certas normas grupais de comportamento tenham sido estabelecidas. Um clique é "um grupo íntimo não-familiar, composto por membros, os quais podem variar em números de 2 a 30 ou mais pessoas". Concluíram que as pessoas se integram às comunidades por relações "informais" e "pessoais", tanto de família quanto de membros de um clique, e não simplesmente por meio das relações "formais" da economia e do sistema político. A passagem de uma pessoa em um clique repercute para fora em uma rede de inter-relações, as quais integram quase toda a população da comunidade em um sistema singular vasto de relações do clique.

Colegas de Warner exploraram a idéia dos cliques (Davis, Gardner e Gardner, 1941, apud Scott, 2004), concluindo que sua estrutura interna poderia ser vista em três "camadas": uma "central", daqueles que participavam mais constantemente e mais intimamente juntos; um "círculo primário", daqueles que participavam conjuntamente com os membros centrais em algumas ocasiões, mas nunca como um grupo próprio; e um "círculo secundário", daqueles que participavam de modo pouco freqüente. Eles sugeriram que a periferia, 
membros das classes mais baixas de um clique, somente era capaz de contatar os membros das classes altas de outros cliques por intermédio dos membros centrais de alta classe de seu próprio clique.

Homans (1950, apud Scott, 2004) centrou-se na idéia de que as atividades humanas levam as pessoas a interagirem com as outras e que essas interações variam em sua "freqüência", "duração" e "direção"; a interação era a base na qual os "sentimentos" se desenvolviam entre as pessoas. Os dados coletados em suas pesquisas foram apresentados em matrizes, sendo um dos primeiros artigos publicados do método da "reordenação de matrizes", análogo ao que foi chamado de "modelagem de blocos". Nadel (apud ibidem), em 1957, definiu uma "estrutura" como a articulação ou a reordenação de elementos para se formar um todo. Para atingir a meta da construção de modelos formais, ele advogava uma abordagem matemática para a estrutura.

A escola dos antropólogos de Manchester desenvolveu-se no Departamento de Antropologia Social daquela universidade, influenciada tanto por RadcliffeBrown quanto pela escola de Harvard. Uma figura central da escola de Manchester foi Max Gluckman, que, em vez de focar os aspectos de integração e de coesão, enfatizava os de conflito e de mudança. Para ele, conflito e poder eram elementos integrais de qualquer estrutura social e sua análise ia aos limites das atividades sempre presentes de negociação, de barganha e de coerção na produção da integração social. Os trabalhos desses antropólogos - entre os quais se destacaram John Barnes e Clyde Mitchell — deu ênfase às estruturas das relações das redes, combinando as técnicas formais de análise de redes com conceitos substantivos da sociologia.

Atribui-se a Mitchell (1969, apud Scott 2004) o desenvolvimento das bases para uma pesquisa sistemática da análise das redes sociais. Com ênfase na matemática da teoria dos grafos, juntou-as com a pesquisa sociológica para poder esclarecer as propriedades estruturais da organização social. Barnes generalizou as concepções de Mitchell, da esfera das relações interpessoais para aquelas de "ordem pessoal". Ordem pessoal seria "o padrão de ligações pessoais individuais que se tem com um conjunto de pessoas e as ligações que essas pessoas têm ao seu redor". Cada rede interpessoal seria construída por duas formas diferentes de ação, combinadas de várias maneiras para formar a rede de interações concreta. Há, em primeiro lugar, "comunicação", que envolve a transferência de informação entre os indivíduos, o estabelecimento de normas sociais e a criação de um grau de consenso. Por outro lado, há o "instrumental" que envolve a transferência de bens materiais e de serviços entre as pessoas. Assim, redes sociais particulares envolveriam tanto um fluxo de informações quanto uma transferência de recursos e de serviços. 
Redes interpessoais poderiam ser analisadas pela descrição da qualidade das relações envolvidas: a sua "reciprocidade", "intensidade" e "durabilidade". Muitos relacionamentos envolvem uma transação ou uma troca, e assim podem ser considerados "direcionados" de uma pessoa para outra. Uma importante medida das relações é o grau pelo qual a transação ou a orientação é "recíproca". "Durabilidade" foi definida como a medida de como duram as relações e suas obrigações subjacentes. "Intensidade" referia-se à força das obrigações envolvidas nas relações. "Densidade" foi vista como a totalidade da rede: a extensão para a qual todas as relações atualmente presentes tenderiam, podendo ser usada para descrever a textura da rede social. "Alcance" referia-se a quão fácil é para todas as pessoas se contatarem com todas as outras, por meio de um número limitado de passos.

Duas inovações foram elementos-chave no desenvolvimento das análises de redes sociais, até chegarmos ao atual estado-da-arte: o desenvolvimento de modelos algébricos de grupos, usando a teoria dos conjuntos para modelar ligações familiares e outros tipos de relações; e o desenvolvimento de escalas multidimensionais - uma técnica de "escalonamento" para transformar relacionamentos em "distâncias" sociais e para o mapeamento delas em um espaço social (Scott, 2004).

O fenômeno dos mundos pequenos despertava o interesse de diversos pesquisadores. Milgram (1967, apud Watts, 1999)

realizou a primeira abordagem experimental desse problema, por meio do envio de uma série de cartas rastreáveis de pontos de origem situados no Kansas e em Nebraska para um ou dois destinatários em Boston. Essas cartas só poderiam ser enviadas para pessoas que os remetentes conhecessem pelo primeiro nome e deveriam ser reenviadas por esses destinatários da mesma forma exigida para os primeiros remetentes. Milgram conseguiu rastrear tanto as características demográficas quanto as das pessoas que participaram desse experimento. Os resultados indicaram que havia um comprimento médio da cadeia entre correspondentes de aproximadamente seis, o que deu suporte à noção dos "seis graus de separação", que até hoje nos surpreende, porque a construção consciente dessas cadeias de intermediários é muito difícil de ser realizada.

Granovetter (1973, apud Watts, 1999) — em estudo clássico sobre como as pessoas conseguiam se empregar nos diferentes mercados de trabalho - desenvolveu os princípios da teoria da força das ligações fracas. Partindo de sua motivação pessoal causada pela leitura de trabalhos de Rapoport e Horvath (1951), observou um tema importante e pouco explorado — as ligações fracas são instrumentos cruciais que as pessoas precisam ter para a total coesão social. 
Em sua pesquisa, perguntava aos entrevistados se julgavam que as informações que levaram à obtenção de trabalho eram provenientes de "amigos" e obtinha usualmente a seguinte resposta: "Não, somente de um conhecido". Esse ponto de vista popularizou-se na sociologia americana e estimulou muitos outros estudos mostrando que métodos de escolha "racionais" para se obter informação de emprego eram de pouca importância; ao contrário, a probabilidade de uma pessoa conseguir uma mudança de emprego dependia da proporção de contatos de trabalho que possuía e que estavam em ocupações diferentes das suas próprias.

As conclusões provenientes dessa teoria nos dizem que indivíduos com maior número de ligações fracas possuem maiores oportunidades de mobilidade. Segundo a teoria da autonomia de Coser (1975), construída com base em Simmel (1950, apud Watts, 1999), muitas ligações fracas propiciam "terreno propício para a autonomia dos indivíduos". Pessoas com muitas ligações fracas (o Gesellschaft de Tönnies, 1950) convivem socialmente com as expectativas de diferentes lugares e em diferentes épocas, as quais tornam possível a preservação de um núcleo interno, retendo atitudes internas ao mesmo tempo em que se conformam às várias expectativas. Pessoas com ligações fortes (o Gemeinschaft) seguem normas tão rígidas que são necessários esforços pequenos para atender às expectativas uns dos outros.

Granovetter (1973, apud Granovetter, 1983) argumentava que as estruturas sociais das camadas menos favorecidas da população são baseadas em ligações fortes, as quais não encorajam atuações comunitárias complexas, o que, em troca, desenvolveria maior flexibilidade intelectual e autodirecionamento. Já as ligações fracas conduzem a atuações comunitárias mais complexas, possibilitando maior flexibilidade cognitiva e desenvolvendo a habilidade das comunidades de se organizarem. Quanto maior a quantidade de ligações fracas, maior a capacidade de atuar em conjunto. Ligações fortes formam maior coesão local, porém têm como conseqüência um maior grau de macrofragmentação das sociedades.

As ligações fracas entre os indivíduos e seus conhecidos, entretanto, não são meramente ligações de conhecimentos triviais, mas uma ponte crucial para a ligação entre duas árvores formadas densamente por amigos próximos. Essas duas árvores não podem, de fato, estar conectadas entre si em todos os níveis, se não houver a existência das ligações fracas. Em conseqüência, indivíduos com poucas ligações fracas serão privados de informações de partes distantes do sistema social e confinados às notícias e às visões provincianas de seus amigos mais próximos. Isso os leva a ficar em desvantagem no mercado de trabalho, tendo dificuldades para se integrar em movimentos políticos ou de qualquer tipo, uma vez que as organizações orientadas por metas tipicamente resultam 
de "recrutamento" entre amigos. Sem as ligações fracas, qualquer movimento gerado não se desenvolverá fora dos cliques. A visão macro desse argumento é que os sistemas sociais que não contenham ligações fracas serão fragmentados e incoerentes, novas idéias circularão de forma lenta, o conhecimento científico será prejudicado e haverá a formação de subgrupos raciais, étnicos ou geográficos, que terão dificuldades em estabelecer um modus vivendi.

A idéia de que as redes podem ser divisíveis em subgrupos cooperativos que não cooperam com os demais subgrupos foi posteriormente refutada pelo entendimento de que essas proximidades podem ser mais ou menos densamente conectadas. Definiu-se densidade como o elemento $v$ das redes, calculado pela proporção de todas as possíveis conexões de $v$ com suas vizinhanças imediatas existentes. Essa análise atentou para o aparecimento de duas escalas que deveriam ser desenvolvidas: a do conceito de equivalência estrutural e a técnica de modelagem de blocos.

De acordo com Lorrain e White (1971, apud Watts, 1999), " $a$ é estruturalmente equivalente a $b$ se $a$ se relaciona com todos os objetos $x$ de [uma categoria] $C$ do mesmo modo que $b$ também o faz. Do ponto de vista da lógica da estrutura, uma vez que $a$ e $b$ são absolutamente equivalentes, eles são substituíveis". Já a modelagem de blocos (White, Boorman e Breiger, 1976, apud ibidem) considera as redes como compostas por blocos de elementos estruturalmente equivalentes e representam o gráfico em termos dos relacionamentos entre esses blocos.

Para Watts (1999) as únicas redes cujas propriedades estatísticas são tratáveis analiticamente são aquelas completamente ordenadas ou completamente randômicas. Infelizmente, os sistemas sociais reais aparentam se localizar entre esses dois extremos. Três questões centrais permaneceriam em aberto:

v redes sociais exibem características estruturais que são inerentemente nãolocais, então nenhuma análise puramente local pode predizer seus aspectos estatísticos globais;

$\checkmark$ as dificuldades analíticas crescem com o tamanho das redes;

v é desconhecido onde repousa a gama de variação das estruturas das redes sociais reais, mas nenhum tratamento tem sido dado para as propriedades das redes de famílias contínuas, cujas propriedades estruturais variam o tempo todo de um extremo para outro, com a intenção de se determinar o local e a natureza de alguma transição que ocorra entre eles.

Os métodos usados para acessar os parâmetros atuais das redes têm revelado que qualquer tentativa de se estimar esse tipo de dado esbarra em graves problemas: 
$\checkmark$ muitas pessoas tendem a subestimar o número de amigos de confiança;

v artifícios metodológicos que evitam essa dificuldade são intensamente demorados e trabalhosos;

จ os números mudam com o tempo;

v os números são altamente sensíveis à definição de contatos ou de relacionamentos "significativos" ou "substantivos".

Uma objeção similar é a definição de "distância social": conhecimento, como medida de distância, pode variar largamente, dependendo de qualquer uma ou de todas as seguintes razões: da tendência do observador; da questão que está sendo proposta; dos membros da rede em questão.

Granovetter, ao realizar, em 1983, a reanálise de seu clássico de 1973, concluiu que:

\begin{abstract}
A maior necessidade para o desenvolvimento das idéias de redes de trabalho é o movimento que deve ser feito de se sair de análises estáticas, que observam sistemas em um determinado ponto do tempo, e perseguir sistematicamente a importância de como os sistemas se desenvolvem e mudam. Somente a observação cuidadosa da dinâmica do problema permitirá que a análise das redes sociais cumpra suas promessas, como uma poderosa ferramenta na análise da vida social.
\end{abstract}

\title{
A teoria dos grafos e os grafos de colaboração
}

Segundo Locke (2004) e Boaventura Netto (2003), atribui-se o início dos estudos sobre a teoria dos grafos à proposição e a solução de uma charada matemática por parte do matemático e geômetra Leonhard Eüler (1707-83), que discutiu a possibilidade de se percorrer (ou não) toda a cidade de Konigsberg (hoje chamada Kaliningrado) cruzando cada uma de suas pontes sobre o rio Pregel exatamente uma só vez. Boaventura Netto ressalta, ainda, que talvez pela pouca importância dessa proposição diante da fantástica produção de Eüler, os estudos das teorias matemáticas das relações dos conjuntos discretos só vieram a se tornar objeto de maiores atenções já no século XX, com a publicação, em 1936, do primeiro livro sobre a teoria dos grafos - Theorie der Endlichen und Unendlichen Graphen, de Denes König. Wilson e Watkins (1990, apud Watts, 1999) deram a seguinte definição para o que venha a ser um grafo:

Um grafo $G$ consiste em um grupo não-vazio de elementos, chamados vértices, e uma lista de pares não-ordenados desses elementos, chamados linhas de co- 
nexão. O grupo de vértices do grafo $G$ é chamado grupo vertex de $G$, denotado por $V(G)$, e a lista de linhas de conexões é chamada de lista de conexões de $G$, denotada por $E(G)$. Se $v$ e $w$ são vértices de $G$, então uma linha de conexão de forma $v w$ é dita como sendo uma ligação ou uma conexão de $v$ e $w$.

O número de vértices em $V(G)$ é denominado a ordem (n) do grafo, e o número de conexões em $E(G)$ é denominado seu tamanho $(M)$. Os vértices representam os elementos da rede e as ligações representam alguns relacionamentos predefinidos entre os elementos conectados. A teoria dos grafos geralmente lida somente com o número de elementos na rede e com os seus relacionamentos com respeito a cada outro, em termos de características do grupo de ligações.

Segundo Scott (2004), muitas características fundamentais das redes sociais podem ser analisadas por meio da manipulação direta de matrizes. Embora as matrizes sejam úteis para a organização e para a armazenagem de dados relacionais, programas específicos de computador possibilitam uma abordagem muito mais fácil e direta para a análise de redes. A abordagem matemática da teoria dos grafos provê uma linguagem formal para se descrever as redes e suas características, e, assim, fornece uma tradução de dados matriciais para conceitos formais e teoremas, os quais podem ser diretamente relatados às características fundamentais das redes sociais.

É necessário, primeiro, se considerar os tipos de linhas que podem ser usadas na construção dos grafos. As linhas podem corresponder a qualquer tipo de dados relacionais: não-direcionados, direcionados, ponderados, tanto direcionados quanto ponderados etc. Destacam-se, a seguir, as principais medidas associadas a um grafo.

A matriz de adjacências $M(G)$ é a matriz $n \times n$ na qual $M_{i, j}$ é o número de conexões unindo os vértices $i$ e $j$. No caso de (grafos) não-ponderados, todas as entradas devem ser 0 ou 1 (ou booleanas). Computacionalmente essa representação tem o inconveniente de que a grande quantidade de zeros contidos na matriz despende uma área de memória expressiva, já que essas matrizes são significativamente esparsas. Segundo Watts (1999), um diagrama de grafo tenta representar cada linha e cada coluna em uma matriz de incidências por um ponto no papel. Uma vez que a matriz de adjacências apropriada tenha sido derivada, as entradas "0" ou "1" nas células da matriz, representando a presença ou a ausência de uma relação, pode ser indicada pela presença ou pela ausência de linhas entre os pontos.

Uma estatística freqüentemente referenciada é a chamada grau médio do grafo ( $k$ ), que quantifica o relacionamento entre $n$ e $M$ (onde $M=(n . k) / 2$ ). O efeito correspondente em $k$ das condições de dispersão é que os grafos devem ter $k<<n$. Watts (1999) destaca que uma das estatísticas mais importantes 
dos grafos a ser considerada é a extensão característica do percurso $(L(G))$, que é a distância típica $d(i, j)$ entre todo vértice e todos os outros vértices. Distância aqui é tratada como o número mínimo de conexões que necessita ser utilizada para que se alcance o vértice $j$ partindo do vértice $i$, ou, em outras palavras, a menor extensão do percurso entre $i$ e $j$. Em um grafo $k$-normal, partindo-se de qualquer vértice, $k$ vértices podem ser alcançados a uma distância 1 . Depois, de cada um desses vértices, outros $(k-1)$ novos vértices podem ser alcançados em uma distância 2 , e assim por diante, sem nenhuma redundância, até que todo o grafo tenha sido alcançado. Como resultado importante, para $k>2$ a extensão característica do percurso em qualquer grafo normal deve crescer, no mínimo, de forma logarítmica com $n$. Para $n$ amplo isso se torna impraticável de se computar exatamente, fazendo com que seja mais fácil se estimar a menor mediana da extensão do percurso. A extensão característica do percurso $(L)$ de um grafo é, então, a mediana das médias das menores extensões dos percursos conectando cada $v \in V(G)$ para todos os outros vértices.

Já a idéia de vizinhança é útil na quantificação de outras estatísticas interessantes para os trabalhos, principalmente o coeficiente de aglomeração (clustering) de um grafo. O coeficiente de aglomeração ( $\underline{v} v$ de $\Gamma(v)$ - a vizinhança de $v$ ) caracteriza a amplitude até a qual vértices adjacentes a qualquer vértex $v$ são adjacentes a cada um. Em termos de analogia de uma rede social, no qual os conhecimentos pessoais de um ator são conhecidos de cada outro e, então, medem a proximidade de $v$ s redes de amizade; $\underline{V}_{v}$ é a probabilidade de dois vértices em $\Gamma(v)$ serem conectados.

O coeficiente de aglomeração de $G$ é $\underline{V}=\underline{v} v$, ponderado para todo $v \in$ $V(G)$. Conseqüentemente, $\underline{V}=0$ implicaria que o grafo correspondente é constituído de $n /(k+1)$ subgrafos desconectados, mas individualmente completos, e $\underline{V}=1$ implicaria que nenhum vizinho de qualquer vértex $v$ é adjacente com qualquer outro vizinho de $v$.

Scott (2004) ressalta ainda o conceito de ponto de centralidade, originado dos conceitos sociométricos de "estrela". Um ponto central era um dos que estava no "centro" de um número de conexões, um ponto com muitos contatos diretos com outros pontos. O mais simples e o mais direto modo para se medir a centralidade de um ponto, no entanto, é pelos graus dos vários pontos no grafo. Um ponto é central, assim, se ele possui um grau alto; o agente correspondente é central no sentido de ser "bem conectado". Uma medida baseada em graus do ponto de centralidade, entretanto, corresponde à noção intuitiva de quão bem conectado um ponto é, dentro de seu ambiente local. Por conta disso, é calculado simplesmente em termos do número de pontos aos quais um ponto particular é adjacente; ignorando-se qualquer conexão indireta que ele possua, o grau pode ser considerado uma medida de centralidade local. É importante 
reconhecer que a medida de centralidade local não envolve a idéia de que haverá um único "ponto centro" na rede.

\section{Metodologia utilizada}

Este artigo analisou o desenvolvimento de uma estrutura particular de difusão de conhecimento, promovida no âmbito dos Enanpads, e como se comportam as ligações entre os atores envolvidos. Os dados analisados foram os artigos publicados nos Anais dos Enanpads, em 2002-04, grupamento de administração da informação, cujos autores foram considerados os atores da rede social e as ligações entre esses atores a estrutura de colaboração das redes sociais na produção acadêmica analisada. Os dados foram obtidos no site da Anpad <www. anpad.org.br>.

A construção da base de dados partiu da codificação dos autores e das instituições, seguida do estabelecimento das ligações entre os atores (autores). A codificação dos autores foi feita segundo as iniciais de seus nomes e respectivas instituições acadêmicas, de forma a contornar o problema de duplicidade verificado com o uso exclusivo da contração dos nomes para suas iniciais. Alguns autores, por lecionarem em mais de uma instituição ou por terem migrado de uma instituição para outra, apresentaram trabalhos por mais de uma universidade. Para efeito de simplificação, nesses casos o autor foi nomeado como pertencente a somente uma universidade, de forma aleatória, ou seja, não foi estabelecido nenhum critério sobre qual instituição é mais relevante do que a outra. Dessa forma, cada autor encontra-se identificado com apenas uma instituição.

As ligações entre os atores foram estabelecidas, em um primeiro momento, pela listagem adequada de quem eram os autores relacionados com o trabalho apresentado, já devidamente codificados e com o número de seu vértice associado. A numeração dos autores foi atribuída por sua ordem de aparição na relação de trabalhos apresentados, iniciando-se em 2002, não obedecendo a nenhum critério hierárquico de importância.

Os dados relacionados ao objeto do estudo foram analisados no Programa Pajek (Program for Analysis and Visualization of Large Networks), versão 1.02, e procedeu-se a uma combinação crescente com os anos $(2002,2002+2003$ e $2002+2003+2004)$, de forma a se verificar o desenvolvimento das estruturas de colaboração ao longo do período estudado.

Em relação às principais medidas relacionadas às redes formadas, foram obtidas as seguintes características principais:

v tabulação da freqüência de ocorrência dos diversos graus de ligação formados; 
- a extensão característica do percurso;

- o grau médio do grafo;

$\checkmark$ o coeficiente de aglomeração;

v a existência de centralidades locais.

Para a obtenção desses resultados, foi utilizada programação específica na geração das matrizes e dos cálculos envolvidos.

\section{Resultados e discussão}

Por se tratar de um trabalho exploratório do estudo das redes sociais e pelas limitações impostas ao tamanho dos artigos, apresentaremos somente o grafo final obtido a partir dos dados estudados. A análise visual do grafo 1 (figura 2), que representa a rede de colaboração final formada entre os autores da área de administração da informação (ADI) dos Enanpads, em 2002-04, indica que a rede social constituída a partir dos grafos de colaboração da produção acadêmica analisada é ainda bastante esparsa. Alguns núcleos ou clusters de autores se formaram ao longo do período estudado, porém esses clusters não apresentam ligações ou pontes uns com os outros. A estrutura de produção acadêmica analisada parece estar fortemente ancorada em produções de autores isoladamente, em duplas, em tríades ou então em figuras próximas às que Watts (1999) denominou "the caveman world" - um mundo no qual "todos que você conhece conhecem todos que você conhece, e ninguém mais". Essa noção visual é corroborada pelos dados apresentados na tabela 2 , entre os quais destaca-se a baixa extensão característica de percurso $(\sim 1,84)$ e de seu grau médio $(\sim 1,88)$.

Conjugando-se as análises visuais com as medidas obtidas, verifica-se que os clusters formados tendem a apresentar uma característica de reprodução endógena, ou seja, no universo amostral pesquisado, infere-se um padrão de produção acadêmica embasada em trabalhos elaborados por autores pertencentes a uma mesma instituição acadêmica. Elas poderiam ser classificadas como ligações fortes, o que, conseqüentemente, indica a existência de poucas ligações fracas, fato que prejudicaria o desenvolvimento e a divulgação de novas idéias. Esse resultado não chega a surpreender, uma vez que se entende que boa parte dos trabalhos submetidos à publicação nos Enanpads é oriunda de teses de mestrado ou de doutorado, as quais obviamente tendem a ter seus autores circunscritos à mesma instituição. 
Figura 2

Grafo 1: rede de colaboração formada entre os autores da área de administração da informação (ADI) dos Enanpads (2002-04)

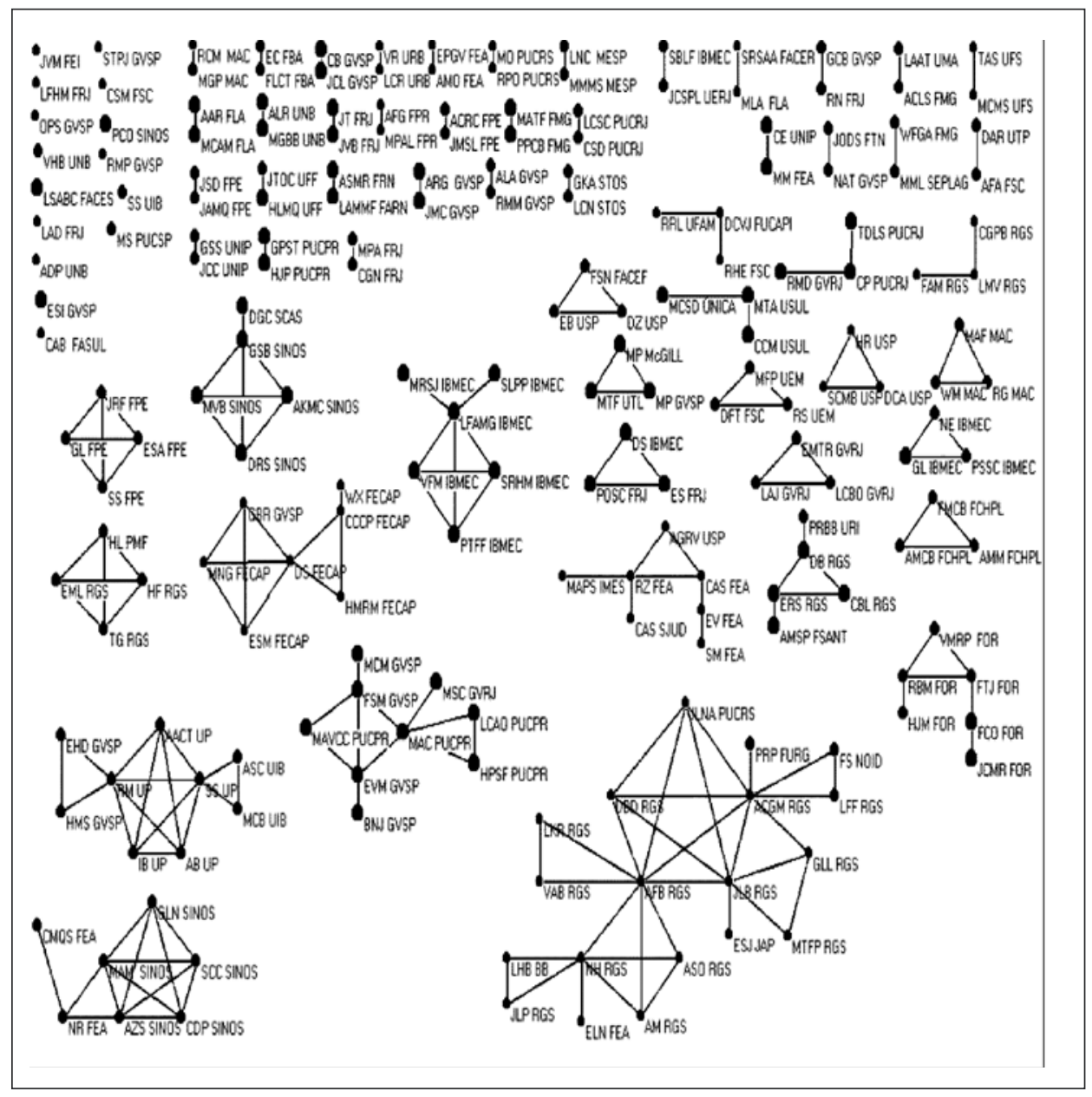

Um dado interessante é refletido no grau de centralidade local estabelecido ano a ano: verifica-se, com o passar do tempo, uma migração dos vértices (autores) com maior grau de centralidade local. Esse fato pode ser explicado pelo incremento do número das ligações de um autor, de um Enanpad para outro, enquanto outros autores não ampliaram suas redes de colaboração nesse período. Esse parece ter sido o caso do vértice 20, o qual possuía em 2002 um grau de centralidade local de 0,0286; em 2003 de 0,0207; fechando o período analisado com o maior grau de centralidade local $(0,0390)$. Ressalta-se que o vértice 28 , que obteve o maior 
grau de centralidade local ao longo do período analisado, iniciou com grau 0,0286 em 2002, cresceu para grau 0,0414 em 2003 e finalizou com 0,0293. Ainda com relação a esse parâmetro, cabe ressaltar que o cluster ao qual pertencia o autor com maior grau de centralidade local em 2002 era formado por autores aglutinados em torno da Unisinos, ao passo que nos dois anos seguintes os autores eram do cluster formado basicamente em torno da UFRGS.

Tabela 2

Resumo dos resultados da rede formada entre os autores da área de administração da informação (ADI) dos Enanpads (2002-04)

\begin{tabular}{|c|c|c|c|}
\hline & \multicolumn{3}{|c|}{ Ano } \\
\hline & 2002 & 2003 & 2004 \\
\hline \multicolumn{4}{|l|}{ Freqüência dos graus (\%) } \\
\hline Grau 0 & 8,4906 & 7,5342 & 7,2816 \\
\hline Grau 1 & 50,9434 & 48,6301 & 43,6893 \\
\hline Grau 2 & 19,8113 & 21,9178 & 24,7573 \\
\hline Grau 3 & 16,0377 & 13,6986 & 13,1068 \\
\hline Grau 4 & 3,7736 & 5,4795 & 5,8252 \\
\hline Grau 5 & 0,9434 & 2,0548 & 2,4272 \\
\hline Grau 6 & - & 0,6849 & 1,4563 \\
\hline Grau 7 & - & - & 0,4854 \\
\hline Grau 8 & - & - & 0,4854 \\
\hline Grau 9 & - & - & 0,4854 \\
\hline Extensão característica do percurso & 1,2178 & 1,4774 & 1,8405 \\
\hline Grau médio do grafo & 1,5849056 & 1,6986301 & 1,8834951 \\
\hline Coeficiente de aglomeração & 0,4811 & 0,6164 & 0,7621 \\
\hline Maior grau de centralidade local & 0,0381 & 0,0414 & 0,0390 \\
\hline Vértices de ocorrência & $63,64,65,66$ & 28 & 20 \\
\hline
\end{tabular}

Outra característica relevante é a extensão característica do percurso, baixa, conforme já comentado, associada à freqüência dos graus de ligação: verifica-se que preponderam as ligações de grau 1 ao longo de todo o período analisado (da ordem de $44 \%$ a 51\%). Graficamente, tentamos representar essas ligações no terço superior do grafo gerado (ver figura 2), separadas em duas classes distintas: as produções efetuadas por autores de uma mesma instituição (ao centro, no alto do grafo); e as produções elaboradas por autores de instituições distintas (à direita, no alto). Nota-se claramente que o padrão de produção é intra-instituição.

Os resultados obtidos neste artigo, embora exploratórios, sugerem um forte embasamento em redes de colaboração intra-universidades. Finalmente, 
sugere-se a utilização de métodos de pesquisa complementares, como entrevistas e questionários, e a ampliação do universo amostral e do período de tempo estudado em estudos posteriores, no intuito de se confirmar (ou não) se os padrões estruturais aqui observados serão mantidos em casos de maior amplitude.

\section{Referências bibliográficas}

ADAMIC, L. A. et al. Search in power-law networks. Physical Review E, v. 64, n. 046135, 2001.

BALTZEL, E. D. Philadelfia gentlemen: the making of a national upper class. Glencoe, Ill.: Imprensa Livre, 1958.

BARABÁSI, A-L. Linked - how everything is connected to everything else and what it means for business, science, and everiday life. New York: Plume Book, 2003.

BARNES, J. A. Social networks. Module in Anthropology, n. 26, p. 1-29, 1972.

BATAGELJ, V.; MRVAR, A. Some analyses of Erdös collaboration graphs. 2004. Disponível em: <vlado.fmf.uni-lj.si/pub/networks/doc/erdos/erdos.pdf> . Acesso em: 1 dez. 2004.

BAVELAS, A. Communication patterns in task-oriented groups. Journal of the Acoustical Society of America, n. 22, p. 271-282, 1950.

BOAVENTURA NETTO, P. O. Grafos: teoria, modelos, algoritmos. 3. ed. São Paulo: Edgard Blücher, 2003.

.Enanpad. 2003. Disponível em: <www.anpad.org.br/frame_enanpad2003. html>. Acesso em: 29 nov. 2004.

CARTWRIGHT, D.; HARARY, F. Structural balance: a generalization of Heider's theory. Psychological Review, n. 63, p. 277-293, 1956.

; __ . A graph theoretic approach to the investigation of system-environment relationships. Journal of Mathematical Sociology, n. 5, p. 87-111, 1977.

COLEMAN, J. S.; KATZ, E.; MENZEL, H. Medical innovation: a diffusion study. Indianapolis: Bobbs-Merrill, 1966.

COSER, R. The complexity of roles as seedbed of individual autonomy. In: COSER, L. (Ed.). The idea of social structure: essays in honor of Robert Merton. New York: Harcourt Brace Jovanovich, 1975.

DAVIS, A.; GARDNER, B. B.; GARDNER, M. R. Deep south. Chicago: University of Chicago Press, 1941. 
FALOUTSOS, M.; FALOUTSOS, P.; FALOUTSOS, C. On power-law relationships of the internet topology. Computer Communications Review, n. 29, p. 251-262, 1999.

FARARO, T. J.; SUNSHINE, M. A study of a biased friendship network. Syracuse: Syracuse University Press, 1964.

FREEMAN, L. C.. Visualizing social groups. Universidade da Califórnia, Irvine, 2002. Disponível em: <moreno.ss.uci.edu/groups.pdf>. Acesso em: 16 nov. 2004.

GARTON, L.; HAYTHORNTHWAITE, C.; WELLMAN, B. Studying online social networks. Journal of Computer-mediated Communication, v. 3, n. 1, June 1997. Disponível em: <www.ascusc.org/jcmc/vol3/issue1/garton.html> . Acesso em: 26 nov. 2004.

GRANOVETTER, M. The strenght of weak ties. American Journal of Sociology, 78, p. 1360-1380, 1973.

The strenght of weak ties: a network theory revisited. Sociological Theory, n. 1, p. 201-233, 1983.

HANNEMAN, R. A. Introduction to social network methods. Universidade da Califórnia. 2001. Disponível em: <faculty.ucr.Edu/\%7Ehanneman?SOC157.NETTEXT. pdf>. Acesso em: 5 dez. 2004.

HOMANS, G. C. The human group. New York: Hartcourt, Brace and Company, 1950.

INSNA (International Network of Social Network Analysis). Computer programs for social network analysis. Disponível em: <www.insna.org/INSNA/soft_inf.html>. Acesso em: 17 dez. 2004.

KÖHLER , W. The mentality of apes. 2. ed. New York: Harcourt, Brace and Company, 1925.

LEWIN, K. Principles of topological psychology. New York: McGraw-Hill, 1936.

LOCKE, S. C. Graph theory. 2004. Disponível em: <www.math.fau.edu/locke/ graphthe.htm>. Acesso em: 31 jan. 2005.

LORRAIN, F. P; WHITE, H. C. Structural equivalence of individuals in social networks. Journal of Mathematical Sociology, n. 1, p. 49-80, 1971.

MAYO, E. The human problems of industrial civilization. New York: Macmillan, 1933.

MILGRAM, S. The small-world problem. Psychology Today, n. 1, p. 62-67, May 1967. 
MITCHELL, J. C. The concept and use of social networks. In: . Social networks in urban situations. Manchester: Manchester University Press, 1969. p. 1-50.

MORENO, J. Who shall survive? New York: Beacon Press, 1934.

NADEL, S. F. The theory of social structure. London: Cohen and West, 1957.

NEWCOMB, T. M. An approach to the study of communicative acts. Psychological Review, n. 60, p. 393-404, 1953.

NEWMAN, M. E. J.; FORREST, S.; BALTHROP, J. Email networks and the spread of computer viruses. Physical Review E, v. 66, n. 035101, 2002.

PAJEK. Program for analysis and visualization of large networks, versão 1.02. 2004. Disponível em: <vlado.fmf.uni-lj.si/pub/networks/pajek/>. Acesso em: 6 dez. 2004.

RAPOPORT, A.; HORVATH, W. J. A study of a large sociogram. Behaviorism Science, n. 6, p. 279-291, 1951.

SCOTT, J. Social network analysis: a handbook. 2004. Não-publicado. Disponível em: <www.analytictech.com/mb119/tableof.htm>. Acesso em: 8 dez. 2004.

SIMMEL, G. The sociology of George Simmel. New York: Imprensa Livre, 1950.

SOLOMONOFF, R.; RAPOPORT, A. Connectivity of random nets. Bulletin of Mathematical Biophysics, n. 13, p. 107-117, 1951.

TÖNNIES, F. Gemeinschaft und Gesselschaft. London: Routledge e Paul, 1950.

WILSON, R. J.; WATKINS, J. J. Graphs: an introductory approach. New York: Wiley, 1990.

WARNER, W. L.; LUNT, P; PAUL, S. The social life of a modern community. New Haven: Yale University Press, 1941.

WATTS, D. J. Small worlds: the dynamics of networks between order and randomness. 8. ed. New Jersey: Princeton University Press, 1999.

WHITE, H. C.; BOORMAN, S. A.; BREIGER, R. L. Social structure from multiple networks. American Journal of Sociology, v. 81, n. 4, p. 730-780, 1976. 